\title{
Ondas sonoras no ensino médio: construção de uma sequência didática
}

\section{Soundwaves in high school: construction of a teaching sequence}

\author{
DA GAMA, Sálvio $F^{1,4}$ \\ XAVIER, Lucas $A^{2,3}$ \\ SEGATTO, Breno $\mathrm{R}^{4}$
}

\begin{abstract}
Resumo
O presente trabalho apresenta uma proposta de sequência didática voltada ao estudo das ondas sonoras para alunos de ensino médio. Buscamos seguir as linhas gerais do que preconiza a Teoria da Aprendizagem Significativa de David Ausubel, que, em síntese, destaca a importância dos conhecimentos prévios dos alunos. Na fase de análise das respostas ao teste, com o auxílio de elementos da análise de conteúdo proposta por Bardin, verificamos traços de evolução, apesar da presença de uma certa resistência às mudanças conceituais.

Palavras-chave: ondulatória, aprendizagem significativae Ensino de física.

Abstract

The present work presents a didactic sequence proposal focused on the study of sound waves for high school students. We seek to follow the general guidelines of what David Ausubel's Theory of Meaningful Learning advocates, which, in summary, highlights the importance of students' prior knowledge. In the analysis phase of the responses to the test, with the help of elements of the content analysis proposed by Bardin, we verified traces of evolution, despite the presence of a certain resistance to conceptual changes.

Keywords: wave, meaningful learning, teaching of physics.
\end{abstract}

\section{Introdução}

A escola pública é um ambiente que apresenta desafios devido às suas especificidades, como o perfil do aluno e sua condição socioeconômica, a formação do professor e suas metodologias de ensino. Os desafios perpassam por políticas públicas, por exemplo, a implementação da Base Nacional Comum Curricular, eixo orientador que busca direcionar para uma educação onde o educando possa ter uma formação completa. Nesse cenário a sala de aula é o nosso espaço para o ensino da Física. Considerando este campo do conhecimento, como elevar a qualidade do ensino de ondulatória? Portanto, é oportuno fazer uma reflexão à luz da Teoria da Aprendizagem Significativa (TAS) e seus pressupostos, a fim de ressignificar o ensino e aprendizagem dos alunos quanto à

\footnotetext{
${ }^{1}$ Escola Estadual de Ensino Médio Ceciliano Abel de Almeida, São Mateus-ES. Brasil. salvios@netscape.net ${ }^{2}$ Escola de Ensino Fundamental e Médio Professora Filomena Quitiba, Piúma -ES. Brasil. lucas.perobas@gmail.com 3Programa de Pós-Graduação em Ciências Naturais, Campos do Goytacazes-RJ. Brasil. lucas.perobas@gmail.com

${ }^{4}$ Universidade Federal do Espirito Santo, Programa de Pós-Graduação em Ensino de Física, Viória-ES. Brasil. breno.segatto@ufes.br
} 
questões do conteúdo de ondas sonoras, por meio de uma sequência didática, que constitui o propósito explicitado neste artigo.

Diante da narrativa exposta e da necessidade de responder ao questionamento anterior, se propõe como objetivo relacionar a TAS com o conteúdo de ondulatória a partir de uma sequência didática e verificar eventuais indícios de aprendizagem significativa. Ausubel (1980) elaborou a TAS com forte elo na estrutura cognitiva do educando:

As variáveis da estrutura cognitiva se referem a propriedades significativas substanciais e organizacionais do conhecimento total do aprendiz num dado campo de conhecimentos que influenciam o seu desempenho acadêmico geral futuro na mesma área de conhecimentos. (AUSUBEL, NOVAK e HANESIAN, 1980, P.141)

Nessa perspectiva é feito o estudo de ondulatória ancorado na TAS afim de investigar e aproximar nosso objetivo do processo de ensino e aprendizagem.

\section{Referial teórico}

Ausubel $(1978 ; 2003)$ salienta da importância de refletirmos sobre a aprendizagem do educando, que deve ser significativa. O que é ensinado na sala de aula deve ter utilidade no cotidiano do educando. Isso nos exige, enquanto educador, pensar em nossas ações. Para esse autor a aprendizagem acontece pelo viés da assimilação de conceitos na estrutura cognitiva do aluno. Para desenvolver uma aula baseada na TAS devemos conhecer os elementos que compõe a teoria. Ausubel at al (1978, prefácio) mostra quanto ao processo educativo que "o fator isolado mais importante influenciando a aprendizagem é aquilo que o aprendiz já sabe. Descubra isso e ensineo de acordo". Ao realizar pesquisas em 1978, Ausubel e colaboradores perceberam que a interação entre docente, discente e o conhecimento no chão da escola, identificaram a aprendizagem mecânica e a aprendizagem significativa. Nessa perspectiva entendemos aprendizagem onde a estrutura cognitiva do indivíduo recrudesce através da internalização de novos conceitos. Esta estrutura já contém conceitos e ideias inicialmente. $O$ relacionamento que ocorre entre as ideias pré-existentes e as ideias novas que são internalizadas determinará o tipo de aprendizado que surgirá, que oscila entre o aprendizado mecânico e o aprendizado significativo.

Aprendizagem mecânica ocorre quando uma ideia não se relaciona de forma lógica e clara com nenhuma ideia pré-existente na estrutura cognitiva do indivíduo, sendo assimilada de forma isolada. Implica numa apropriação conceitual arbitrária, resulta em inflexibilidade no uso do conceito assimilado, tornando-o restrito a um certo contexto e a uma certa linguagem; o tempo no qual perduram as novas ideias caracteriza-se por ser curto. Por outro lado, a aprendizagem significativa é a que provoca mudanças significativas no momento em que uma nova informação ancora em conceitos relevantes preexistentes, de forma não arbitrária (plausível, sensível e não aleatória) e substantiva, na estrutura cognitiva do indivíduo que aprende. A aprendizagem significativa permite a guarda de novas informações por um maior período temporal e de forma mais estável, além de que o emprego do novo conceito se dê de forma independente do contexto em que esse conteúdo foi aprendido.

Outro elemento fundamental da TAS é a diferenciação progressiva, referente ao trabalho em ordem crescente em especificidade, do geral para o específico. Pressupõe-se que as ideias mais gerais servem para a contextualização das ideias menos amplas, que lhes servirão na ancoragem. Entretanto, o docente deve considerar os fatores externos (aula, material instrucional e outras), elementos para adequar condições ao aprendizado significativo dos alunos, assim como, os fatores internos (cognitivos e afetivo-sociais), particulares de cada indivíduo. Na teoria ausubeliana, para que o aluno tenha condições de aprender significativamente, é 
necessário que ele possua disposição para aprender e tenha ideias de esteio na estrutura cognitiva nas quais as novas ideias ensinadas podem se ligar de forma não arbitrária e substantiva.

Kiefer e Pilatti (2014) visando elaborar uma aula baseada na TAS, às quais nos atemos neste trabalho, apresenta sugestões, conforme o Tabela 1, que poderão servir de fomento material ao preparar aulas de acordo com a teoria ausubeliana.

Tabela 1

Sugestões para elaboração de aula no modelo da TAS

\begin{tabular}{|c|c|}
\hline Etapas & Atividades \\
\hline Definição do conteúdo da aula. & $\begin{array}{l}\text { - Selecionar na ementa e/ou no programa do curso ministrado o conteúdo da aula; } \\
\text { - Identificar no currículo ou em pré-testes a existência dos pré-requisitos } \\
\text { necessários; } \\
\text { - Definir os resultados de aprendizagem que se pretende alcançar, vinculados aos } \\
\text { conceitos mais inclusivos; } \\
\text { - Selecionar os conceitos mais específicos relacionados com os conceitos mais } \\
\text { inclusivos. }\end{array}$ \\
\hline $\begin{array}{l}\text { Determinação dos aspectos } \\
\text { mais relevantes do conteúdo e } \\
\text { dos organizadores prévios. }\end{array}$ & $\begin{array}{l}\text { - Determinar os aspectos mais relevantes do conteúdo a ser trabalhado; } \\
\text { - Identificar os organizadores prévios. }\end{array}$ \\
\hline $\begin{array}{l}\text { Sequenciação do conteúdo } \\
\text { curricular. }\end{array}$ & $\begin{array}{l}\text { - Sequenciar os organizadores prévios para a parte introdutória da aula; } \\
\text { - Sequenciar os aspectos relevantes do conteúdo de forma decrescente em sua } \\
\text { amplitude; } \\
\text { - Explicitar eventuais relações entre os diversos conceitos que serão trabalhados. }\end{array}$ \\
\hline Avaliação da aprendizagem. & $\begin{array}{l}\text { - Verificar a retenção/aprendizagem dos alunos, considerando os diversos } \\
\text { conteúdos trabalhados. }\end{array}$ \\
\hline $\begin{array}{l}\text { Estratégia e recursos } \\
\text { instrucionais. }\end{array}$ & $\begin{array}{l}\text { - Definir as estratégias e os recursos instrucionais utilizados para que ocorra uma } \\
\text { aprendizagem significativa. }\end{array}$ \\
\hline Montagem do plano de aula. & - Elaborar o plano de aula. \\
\hline
\end{tabular}

Fonte: Kiefer e Pilatti, 2014

Os conceitos apreendidos, de forma significativa, conforme Ausubel (2003, p.6), "podem ser definidos como objetos, acontecimentos, situações ou propriedades que possuem atributos específicos comuns e são designados pelo mesmo signo ou símbolo". Dessa forma, o professor deve criar condições de ativação do subsunçor específico ou mais pertinente à novas informações.

\section{Metodologia}

A pesquisa, de caráter qualitativo envolveu duas turmas de 2a série do ensino médio, sendo uma do matutino e outra do noturno, na modalidade regular, na Escola Estadual de Ensino Médio Abel de Almeida, situada na região central de São Mateus/ES. Construímos uma sequência didática objetivando tratar do assunto ondas, tendo como pano de fundo os elementos de acústica, isto é, desejamos que nosso plano de aula, constituído por momentos formais em sala, fossem frutíferos dentro do contexto da TAS. Os momentos são mostrados na Tabela 2, sendo o primeiro momento o de levantamento das concepções dos alunos, ou seja, avaliação diagnóstica para o levantamento do que pensam os alunos sobre onda; posteriormente 4 aulas teóricas sobre ondulatória e 1 aula de avaliação. Portanto, foi utilizado questionário estruturado contendo perguntas abertas que, para Sampieri, Collado e Lucio, (2006, P.310), "[...] pode ser usado para coletar os dados, o instrumento é composto de um conjunto de questões de uma ou mais variáveis a serem medidos". 
Tabela 2

Síntese de Sequência didática

implementada na sala de aula

\begin{tabular}{|c|c|c|}
\hline Aulas & Objetivos & Descrição \\
\hline 1 & $\begin{array}{l}\text {-Desenvolver um mapa conceitual envolvendo o conceito de } \\
\text { onda; } \\
\text {-Conceituar natureza das ondas, fontes, frentes de onda, } \\
\text { frequência e período. }\end{array}$ & $\begin{array}{l}\text { Discussão sobre a técnica dos mapas } \\
\text { conceituais (turma noturno); uso dialógico das } \\
\text { informações do texto "Fenômenos periódicos: } \\
\text { você já ouviu falar deles?" utilização do } \\
\text { aplicativo "Som" versão } 2.19 \text { do Phet Colorado. }\end{array}$ \\
\hline 2 & $\begin{array}{l}\text {-Reforçar o conceito de frequência ligando-o ao conceito de } \\
\text { altura e às notas musicais por meio de recursos sonoros; } \\
\text {-Conceituar comprimento de onda, velocidade da onda e } \\
\text { timbre; } \\
\text {-Resolver exercícios com os principais conceitos de } \\
\text { ondulatória abordados. }\end{array}$ & $\begin{array}{l}\text { Aula de interação com uso dos arquivos de } \\
\text { vídeo " } 20 \mathrm{~Hz} \text { to } 20 \mathrm{k} \mathrm{Hz} \text { Human Audio Spectrum" } \\
\text { e "A } 440 \mathrm{~Hz} \text { piano for tuning", além da } \\
\text { utilização de instrumento musical melódico ou } \\
\text { harmônico, régua grande. }\end{array}$ \\
\hline 3 & $\begin{array}{l}\text {-Estudar a propagação de onda em uma corda; diferenciar } \\
\text { propagação transversal da propagação longitudinal; } \\
\text {-Demonstrar relação entre frequência e comprimento de } \\
\text { uma corda; } \\
\text {-Resolver exercícios com os principais conceitos de } \\
\text { ondulatória abordados. }\end{array}$ & $\begin{array}{l}\text { Aula expositiva e interativa com uso de } \\
\text { simulador virtual "Wave on a string", régua, } \\
\text { corda grossa de nylon, violão. }\end{array}$ \\
\hline 4. & $\begin{array}{l}\text {-Rever os conceitos comprimento de onda, ventres e nós de } \\
\text { uma onda; } \\
\text {-Experimento de propagação do som em uma corda (telefone } \\
\text { de barbante); } \\
\text {-Resolver exercícios com os principais conceitos de } \\
\text { ondulatória abordados. }\end{array}$ & $\begin{array}{l}\text { Aula expositiva e experimental com uso de } \\
\text { materiais de alto acesso (barbante de algodão, } \\
\text { copo descartável, cola) para demonstrar que o } \\
\text { som se propaga no barbante. }\end{array}$ \\
\hline 5 & $\begin{array}{l}\text {-Aplicar o conceito de ondas com destaque às diferentes } \\
\text { situações do cotidiano; } \\
\text {-Responder às perguntas elencadas das aulas anteriores; } \\
\text {-Resolver exercícios com os principais conceitos de } \\
\text { ondulatória abordados. }\end{array}$ & $\begin{array}{l}\text { Discussão das aplicações dos conceitos de } \\
\text { ondas mais amplos do dia a dia, com discussão } \\
\text { e resposta às perguntas de aulas anteriores; } \\
\text { resolução de exercícios }\end{array}$ \\
\hline 6 & -Aplicar o teste de verificação da Sequência Didática & $\begin{array}{l}\text { Teste objetivo e discursivo, conceitual, com } 7 \\
\text { questões sobre o som e sua propagação e } \\
\text { modelos }\end{array}$ \\
\hline
\end{tabular}

Fonte: Os autores

No próximo tópico discutiremos os resultados obtidos com a aplicação da sequência didática.

\section{Discussões e resultados}

Foi proposto nas duas turmas a construção de mapas conceituais envolvendo o assunto ondas. Foi explanado para os alunos o que era mapa conceitual. A Figura 1 mostra um mapa sem os conectores, ou seja, uma aluna produziu um mapa mental sobre ondas.

Para Schuhmacher e Brum (2014), o professor precisa compreender que as concepções decorrem dos esforços imaginativos dos alunos ao descrever o mundo físico que eles são capazes de enxergar. Portanto, é um dever profissional considerar a construção pessoal, que deve ser valorizada como um importante elemento que orientará o seu modo de ensinar. A Figura 2 mostra a funcionalidade e potencialidade do simulador e como usufruí-lo didaticamente. Foi um momento que ocorreu na terceira aula, os alunos queriam usá-lo para responder com mais segurança às questões propostas. 


\section{Figura 1}

Concepção inicial de

uma aluna sobre ondas

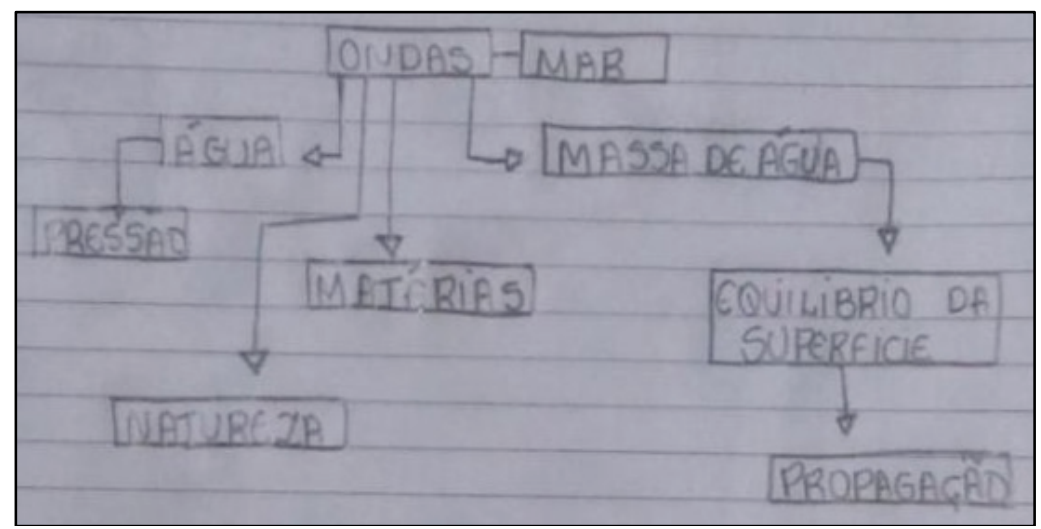

Fonte: Autores

Figura 2

Uso de simulador virtual como auxílio em sala de aula.

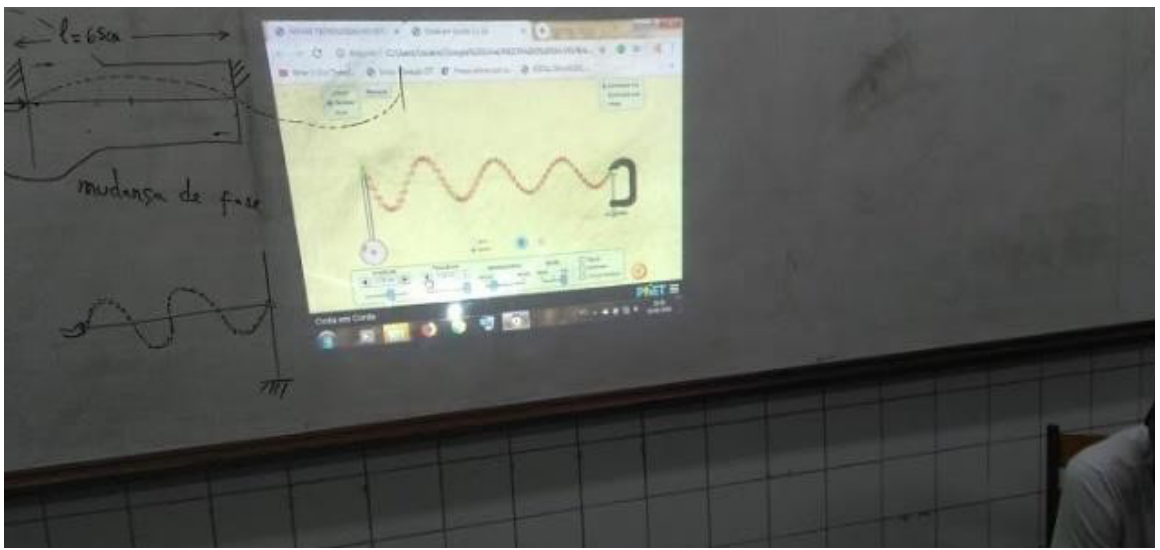

Fonte: Autores

A TAS prevê os conhecimentos que o aluno carrega consigo como o elemento mais importante para a aprendizagem significativa: eles podem ancorar os novos conhecimentos apresentados à estrutura cognitiva do aluno.

Seguimos para o alcance de nosso objetivo, que consiste em verificar eventuais indícios de aprendizagem significativa. O questionário aplicado teve a análise de conteúdo de Bardin (1977), que sintetiza como

[...] um conjunto de instrumentos metodológicos cada vez mais subtis em constante aperfeiçoamento, que se aplicam a «discursos» (conteúdos e continentes) extremamente diversificados. O factor comum destas técnicas múltiplas e multiplicadas - desde o cálculo de frequências que fornece dados cifrados, até à extracção de estruturas traduzíveis em modelos- é uma hermenêutica controlada, baseada na dedução: a inferência. (BARDIN, 1977, p. 9) 
Tomado o padrão de respostas dadas pelos alunos, nos perguntamos inicialmente qual essência da comunicação nos é permitido descrever com nossas ferramentas de auscultação? Qual o padrão - ou quais - estariam na construção epistemológica do discurso do aluno em torno de ondas, mormente as ondas mecânicas?

A Tabela 3 contém as categorias em função das questões propostas aos alunos, apresentando as respostas obtidas em função da aplicação do questionário.

Tabela 3

Categorias das questões

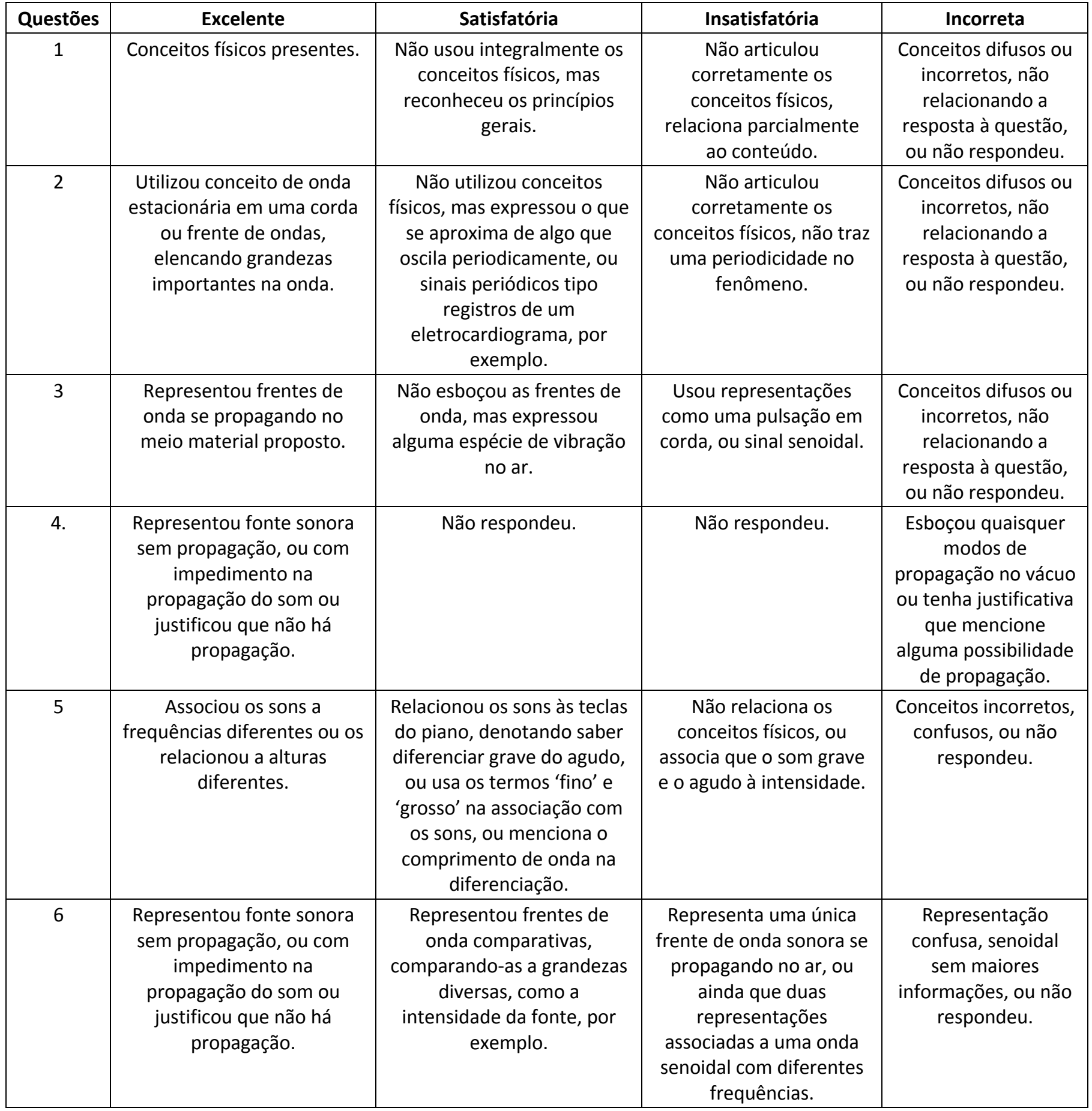

Fonte: Os autores 
Na questão Q1, "o que você entende por onda em Física?", encontramos como categorias dos turnos noturno e matutino, respectivamente Gráfico 1 e 2.

Gráficos 1 e 2

Entendimento de Onda

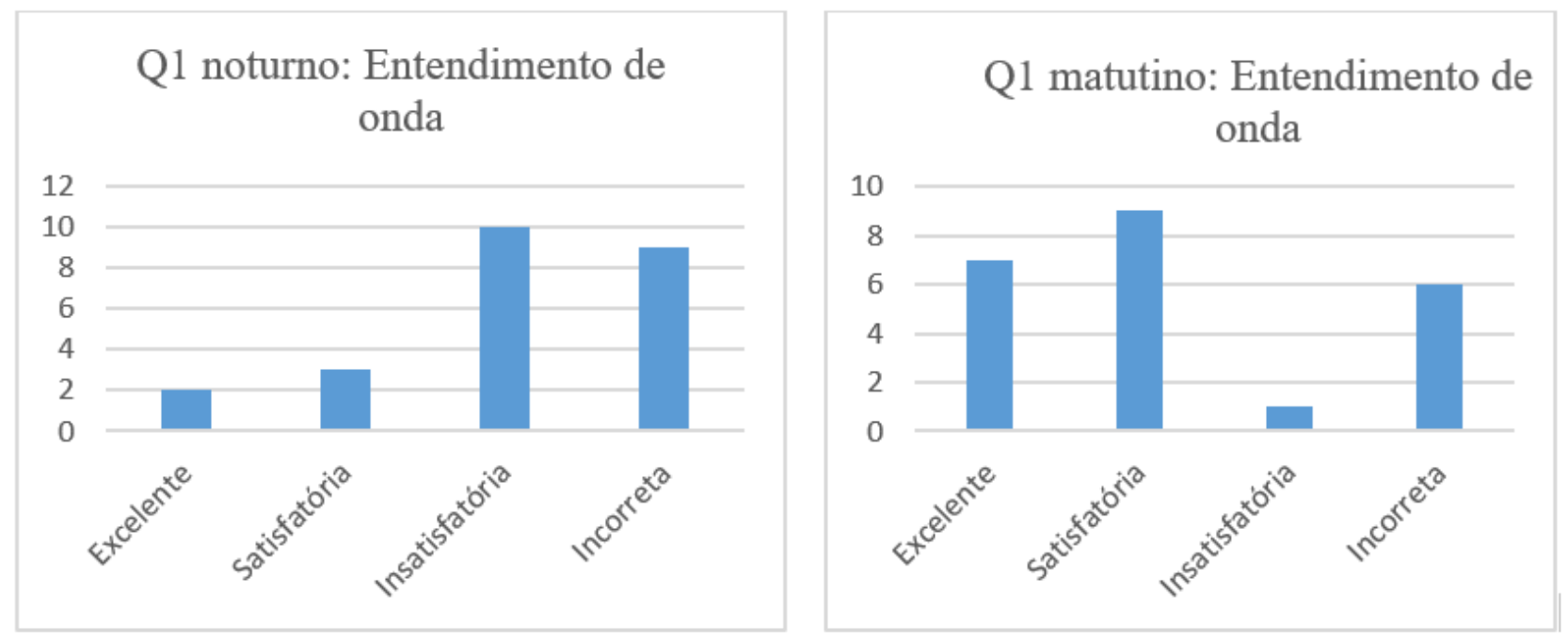

Fonte: Os autores

Importante observar que, não obstante a instrução dos conteúdos sobre ondas, conforme nosso plano de aula, há um percentual de $37,5 \%$ dos alunos do noturno que expuseram conceitos bastante difusos, que não remetiam ao conceito formal, ou que não responderam; no turno diurno essa categoria que denominamos incorreta, conforme Tabela 3, foi representada por $26 \%$ dos alunos.

O exemplo de uma aluna ao responder que onda é uma "grandeza física" (sic), remete a estruturas cognitivas não modificadas segundo a perspectiva da TAS, visto que os conceitos de grandeza física e onda são integralmente dissociados, o que reforça que o conceito de grandeza física, além de não servir como subsunçor para o novo conceito, tem sua compreensão aquém do esperado para a 2a série. Essas ponderações chamam nossa atenção às propriedades intrínsecas ao ensino de física, os conhecimentos prévios dos alunos e suas conexões sociais; tais ponderações aqui nos permitem inferir que ocorrem situações onde os conhecimentos prévios sobre ondas fogem a um nível de difícil categorização quando confrontados com o conceito formal. Gobara et al. (2007) detectou essas divergências quando da detecção dos conhecimentos de alunos do ensino médio em três escolas públicas do Estado do Mato Grosso do Sul, envolvendo a propagação de ondas sonoras no ar, o que sublevou no processo de categorização das soluções ao surgimento da classe 'outros'.

No entanto, houve uma certa resistência cognitiva dos alunos no que tange à questões que demandavam soluções não discursivas ou que exigiam um prospecto pessoal de sua parte. Por essa ampla abertura, tínhamos expectativas de que a questão Q1 nos trouxesse, após o desenvolvimento das aulas, respostas que apresentassem os conceitos físicos trabalhados. Isto é, consideramos que o aluno associasse ondas a vibrações e eventos periódicos, se possível dentro do escopo mais citado que foi onda sonora. Recorrências a outros eventos físicos ondulatórios não devem e nem foram descartados na fase de pré-análise e categorização do material, na perspectiva de Bardin (1977).

Na questão Q2, perguntamos: como você representaria num desenho uma onda, conforme aprendeu em Física? Observe as categorias nas quais distribuímos o padrão das respostas na Tabela 3. Em observação aos dados, 
nota-se que ambas as turmas dão respostas satisfatórias. Um aluno fez um dos esboços (Figura 3) que se aproximam de uma frente de onda sonora, o que pode ser uma demonstração de uma aprendizagem relevante.

Figura 3

Representação de uma frente de onda Trem Bala.

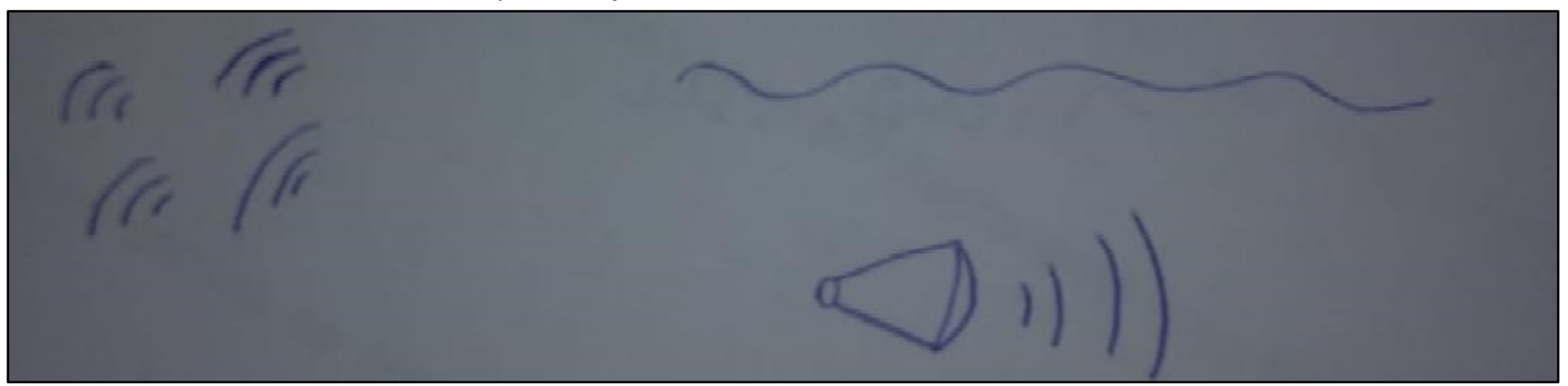

Fonte: Os autores

Na sequência temos o padrão de respostas que a questão Q2 recebeu dos dos alunos pertecentes aos turnos, noturno e matutino (Gráfico 3 e 4).

\section{Gráfico 3 e 4}

Representação de ondas

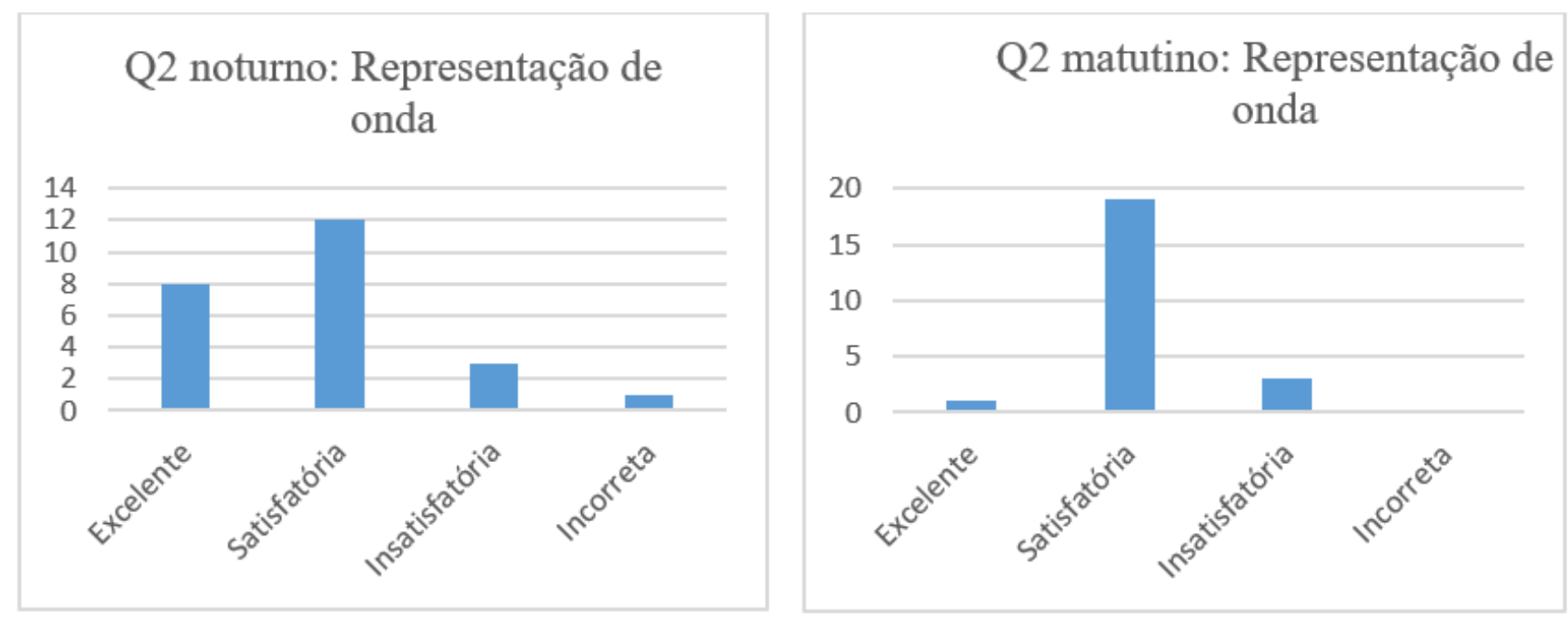

Fonte: Os autores

Podemos concluir que, a representação de uma onda numa boa percentagem com uma concepção satisfatória, $82 \%$ para o turno da manhã e $50 \%$ para o turno noturno, ou ainda, $57 \%$ de todos os alunos avaliados, mostra que até um ponto razoável, houve consistência conceitual que podemos qualificar como possibilidade de aprendizagem significativa.

Na questão Q3, perguntamos: como uma onda sonora se propagaria no ar? Represente num desenho. Observe as categorias para as soluções dadas (Tabela 3). Esperava-se detectar no aluno indícios dos saberes acerca da especificidade do modo de propagação do som no ar, representando suas frentes de onda. O que normalmente ocorre, segundo Gobara et al. (2007), é uma associação dessa propagação com a forma senoidal ou com uma pulsação de uma corda. 


\section{Gráfico 5 e 6}

Propagação de onda no ar
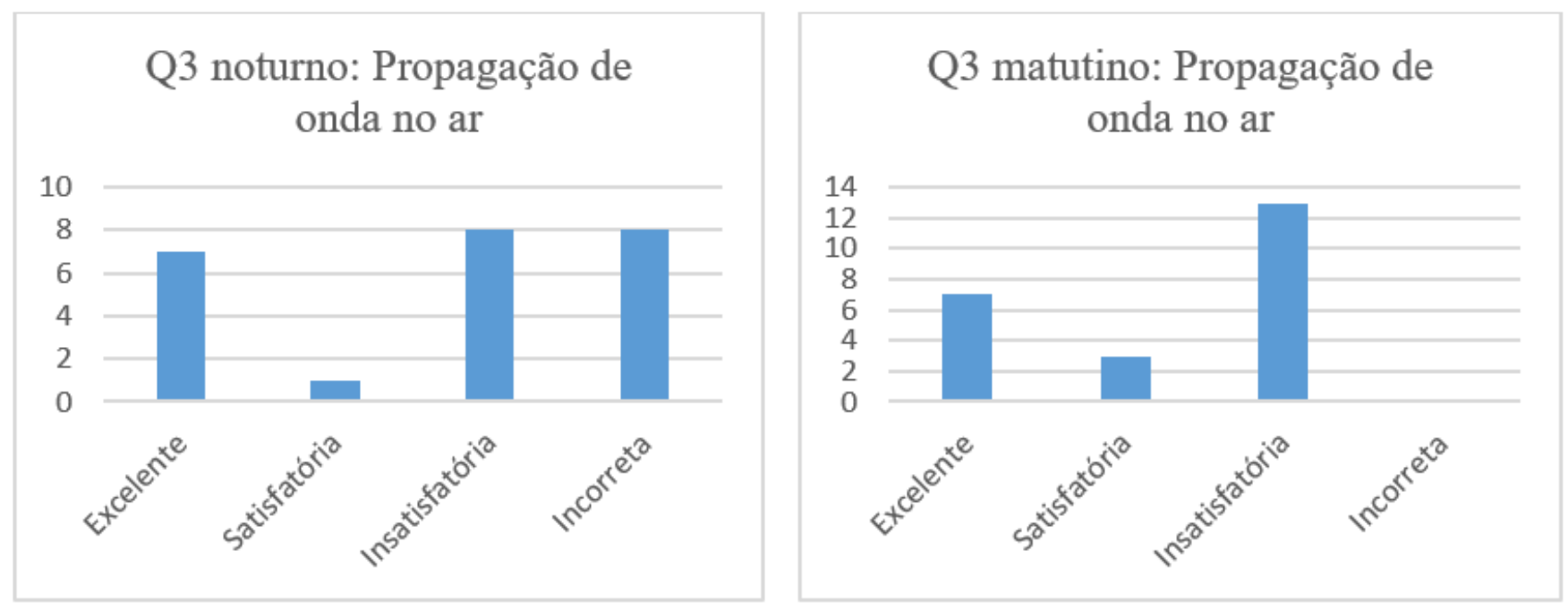

Fonte: Os autores

O padrão mais lembrado em sua pesquisa foi aquele de ondas propagando-se na água - acima de $45 \%$, novamente com influência razoável da porção geográfica. Em termos totais teríamos uma classificação insatisfatória para praticamente a metade de todas as soluções apresentadas (49\%), incluindo os dois turnos. Isso nos permite a reflexão acerca da confusão gerada na propagação das frentes de onda sonora no ar com a representação matemática e gráfica de um impulso senoidal.

Observemos as devolutivas na forma gráfica dos alunos. A Figuras 4, mostra a representação exposta pelo aluno do noturno, denotando um padrão senoidal de propagação do som no ar ou, ainda, a possibilidade de pulsação em corda e a Figura 5, modelo misto que envolve uma propagação senoidal com papel importante das moléculas do ar. As imagens representam uma entidade transportada ou transferida por moléculas no ar (Linder e Erickson, 1989).

Figuras 4 e 5

Padrão senoidal de propagação do som e com transferência de moléculas de ar.
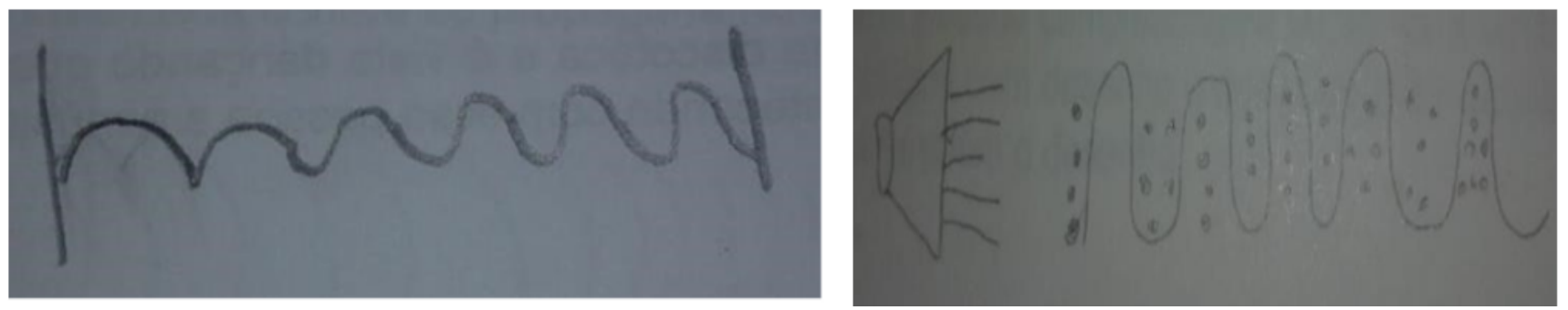

Fonte: Os autores

Na questão Q4 indagamos: como uma onda sonora se propagaria no vácuo? Represente num desenho. Na análise, conforme a tabela 3, observamos que tivemos que categorizar as respostas de maneira que abarcássemos os alunos que não responderam, porque há uma clara possibilidade de que os mesmos abstiveram por simplesmente não terem compreendido o conceito da não propagação de ondas mecânicas no vácuo. Essa abstenção de respostas, conforme Gráficos 7 e 8, também pode estar associada à não compreensão do conceito de vácuo na física, haja vista que este conceito requer uma atividade psíquica interna em torno da abstração. 


\section{Gráfico 7 e 8}

Propagação de onda no vácuo
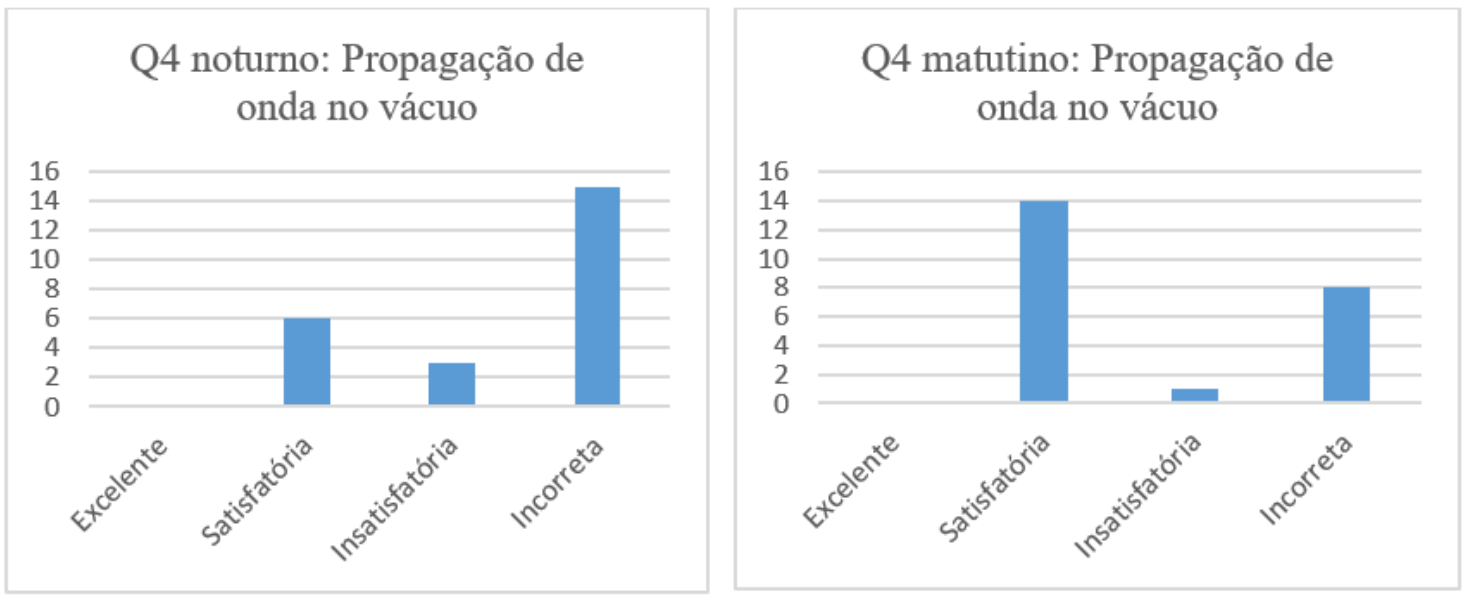

Fonte: Os Autores

Atentando para as observações de Gobara et al. (2007), em cujo trabalho o vácuo não foi mencionado diretamente nas soluções apresentadas pelos alunos em relação à propagação do som, nem tampouco descartado também como uma possibilidade, aqui o problema já o especifica como meio de propagação.

Na Figura 6, o aluno do noturno expõe uma representação que suscitaria dúvidas quanto ao seu modelo de representação; no entanto, descreveu pertinentemente que a onda "não se propaga no vácuo". A mesma ideia de representação mental da não propagação do som no vácuo ocorre com o aluno de codinome Arcan Cosmic (Figura 6), demonstrando consciência do fato físico afirmado.

\section{Figura 6}

Representação e justificativa de um aluno sobre a propagação de uma onda sonora no vácuo

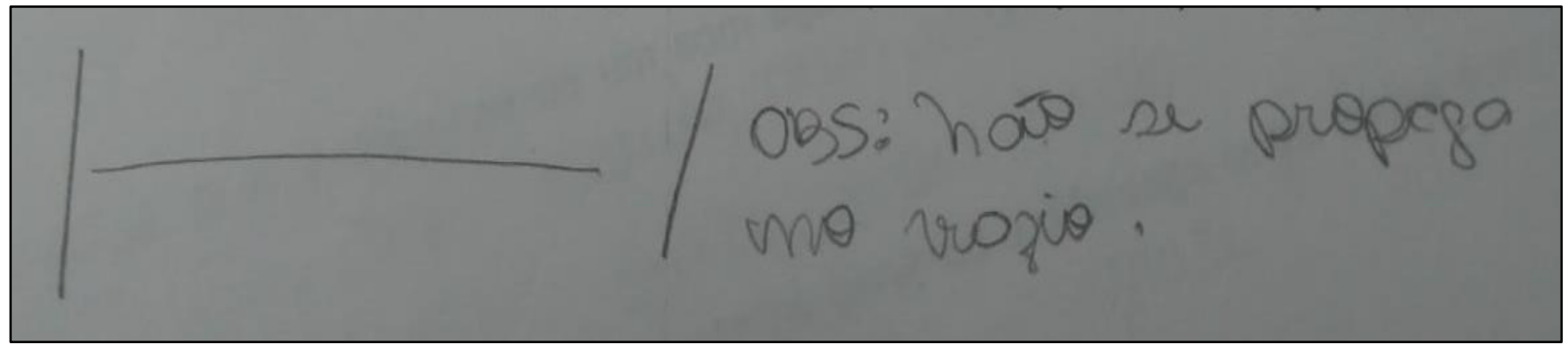

Fonte: Os autores

No entanto, as ocorrências categorizadas como incorretas no turno noturno (62,5\%), chamam a atenção para uma tendência cognitiva com propensão a crer numa propagação do som no vácuo. Vide o aluno Silvio Santos, nome fictício, do turno da manhã que representou uma onda com essa possibilidade (figura 7). 
Figura 7

Representação sobre a possibilidade de propagação do som no vácuo foi recorrente, como ilustra a resposta de um aluno do matutino

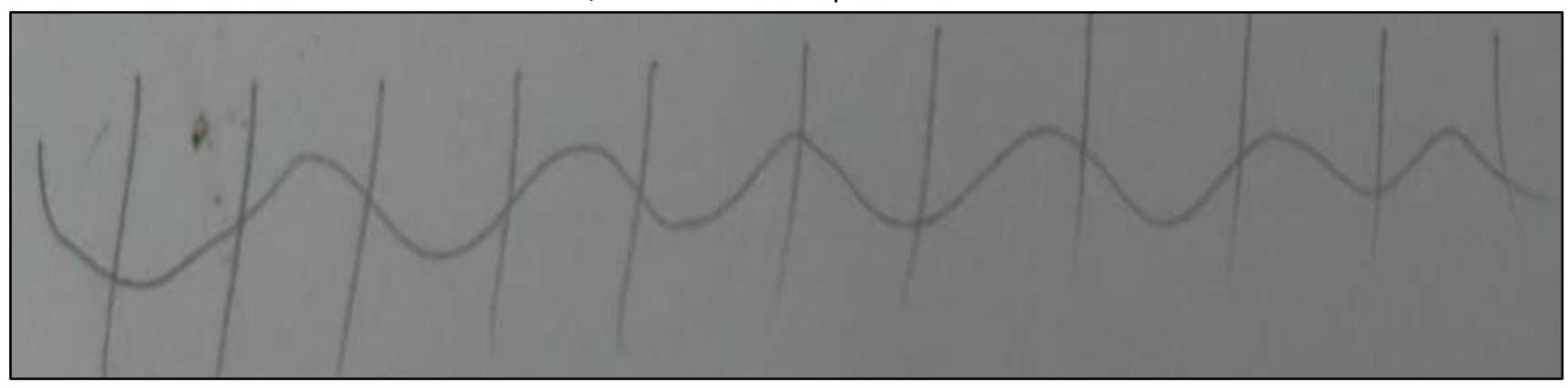

Fonte: Os autores

O que demonstra de fato ser uma provável persistência das concepções espontâneas sobre ondas é o grau elevado de respostas categorizadas como incorretas ( $57,5 \%$ considerando o universo de todos os alunos). Como já observamos, parece que, na concepção do aluno, a propagação se dará através de um meio e ele não abstraiu a diferença entre esse 'novo' meio e o meio ordinário que é o ar.

A seguir a questão Q5 aborda "qual a diferença de um som agudo para um som mais grave, ambos de um mesmo piano?", onde esperávamos que associassem os sons graves e agudos às suas respectivas frequências.

Os gráficos 9 e 10 mostram as soluções apresentadas pelos alunos, discriminadas na tabela 3.

\section{Gráfico 9 e 10}

Diferenciação de som agudo e grave no piano
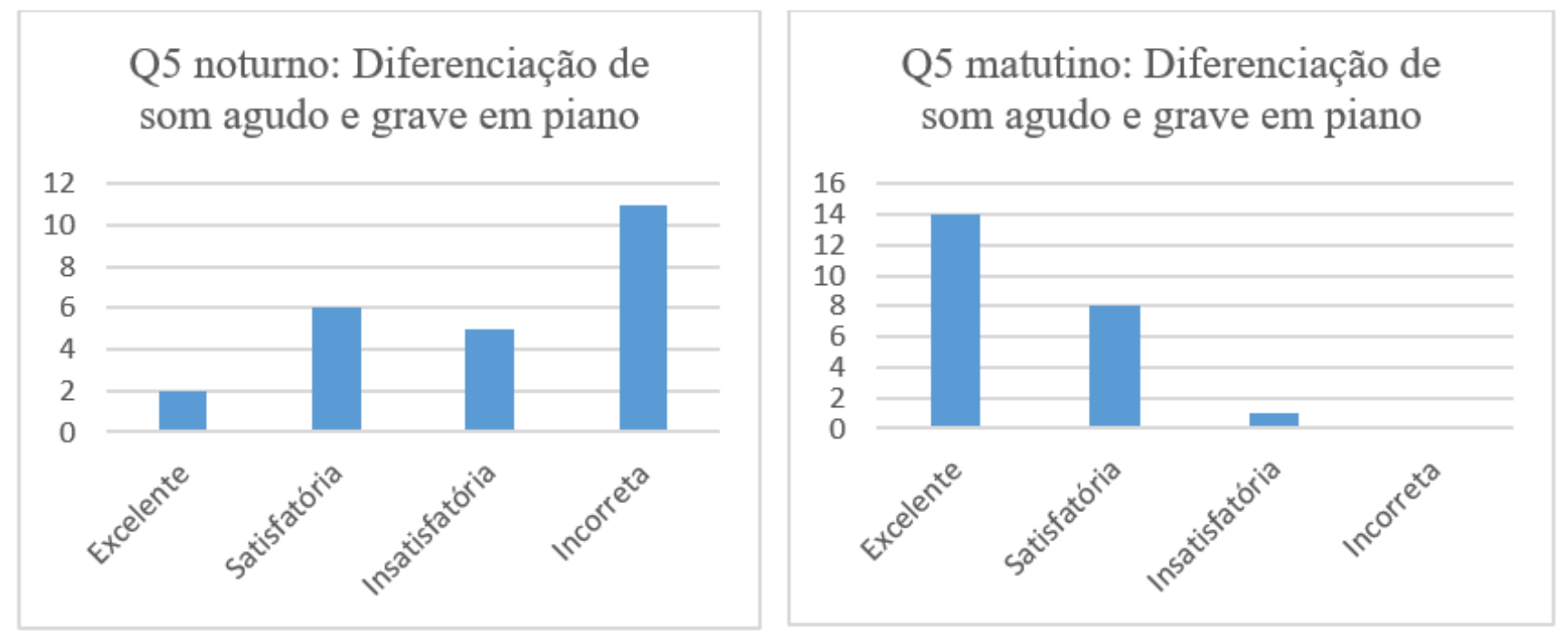

Fonte: Os Autores

Podemos notar que os alunos usaram os termos 'alto' e 'baixo' para significar volume (ligado à intensidade do som), o que nos parece confirmar que, sobre a linguagem e leitura/interpretação da linguagem associada ao conceito físico, os alunos não conseguiram associar satisfatoriamente a representação matemática (amplitude, frequência, comprimento de onda, velocidade de propagação e a influência do meio) à onda em si.

É como se a onda fosse algo abstrato que se propaga indefinidamente, uma ideia de senso comum que prevalece mesmo após as aulas, isto é, a sequência didática auxilia o aluno satisfatoriamente na aproximação entre a concepção de senso comum e o modelo físico, porém, no que se refere ao abandono, por parte do aluno, da concepção de senso comum e a adoção do modelo científico fica a desejar; nesse sentido, é possível sinalizar 
que a sequência didática, na forma como se apresenta, não possibilita o alcance da transição completa, que seria, a identificação de concepção do senso comum, a transição para o modelo científico e este como parte da linguagem do aluno ao falar do fenômeno estudado.

A questão Q6 prossegue à abordagem dos sons agudos e graves, solicitando ao aluno mostrá-los em propagação no ar ("represente com um desenho genérico a diferença entre esses sons se propagando no ar").

A Tabela 3 mostra as categorizações dos padrões encontrados nas respostas dos alunos. E os Gráficos (11 e 12) estão as respostas à questão.

\section{Gráfico 11 e 12}

Diferenciação de som agudo e grave no ar

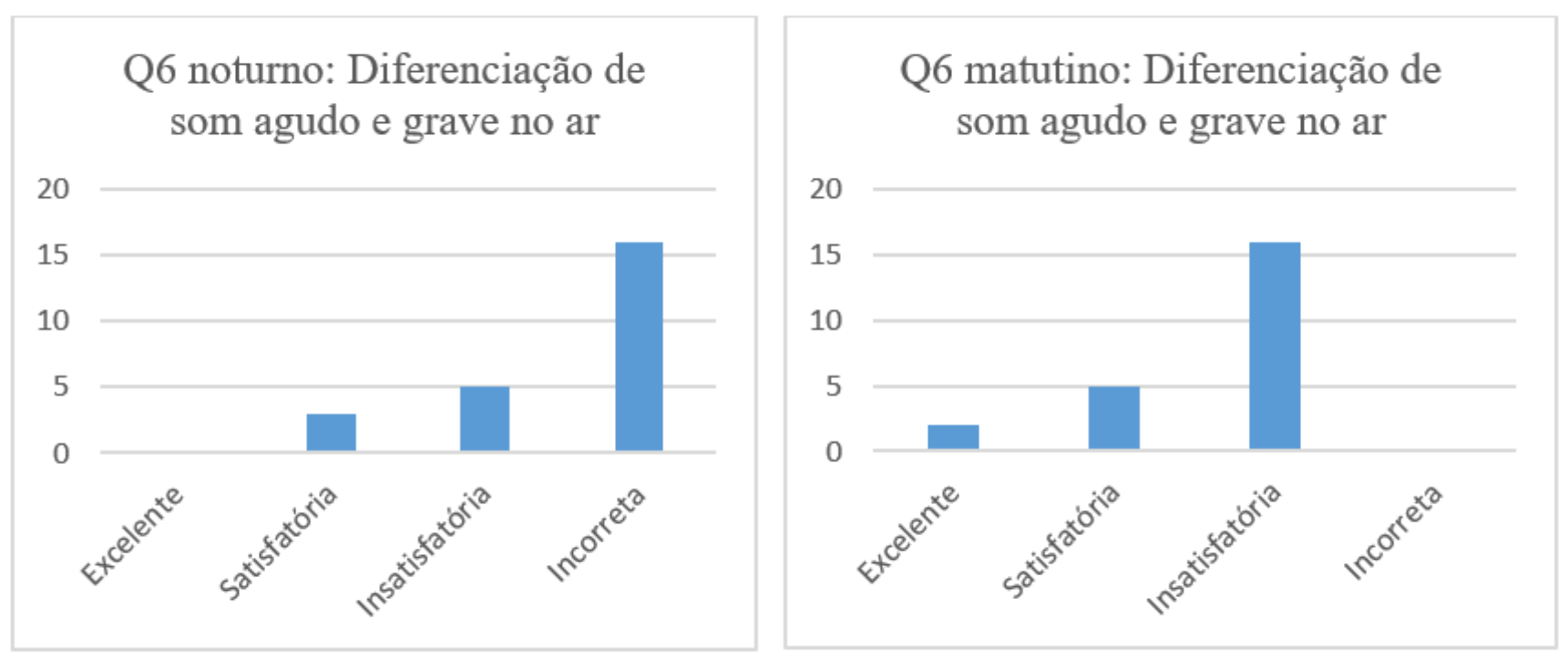

Fonte: Os Autores

A questão Q6 traz, paralelo à questão Q3, um problema de representação de uma onda se propagando no ar, porém no que tange aos sons agudos (maior frequência) e graves (menor frequência). Nota-se que um número significativo de estudantes respondeu adequadamente à questão Q3, expondo desse modo uma fragilidade conceitual ao representar uma onda sonora como uma pulsação senoidal; depreende-se, assim, que o aluno fez aqui uma associação com as primeiras discussões sobre frequência em uma corda. $O$ termo 'genérico' no enunciado foi previamente combinado para ser algo livre, ainda que dentro do contexto estudado, para não induzir o aluno a uma única ideia possível.

Pensando na reconciliação integrativa percebemos, na prática, que ela se processa simultaneamente à diferenciação progressiva, as perguntas elaboradas pelos alunos e o seu papel ativo sobre o novo conhecimento, favorecem as trocas de informações e conceitos na sua estrutura cognitiva, se dão em tempo real, isto é, o tempo todo. Para Moreira (2012), no fim das contas, planejando a partir do material instrucional, teremos um processo na dinâmica cognitiva do aluno onde as diferenças entre conceitos aparentemente semelhantes, as dúvidas e inconsistências são eliminadas, além da integração de significados e ideias ocorrer num nível mais elevado que o anterior.

\section{Conclusões}

O que se pode afirmar acerca do alcance da Sequência Didática proposta? Há que se observar que não buscamos comparar as duas turmas em seus aspectos cognitivos. Ocorreram leituras e interpretação conceitual de tais 
turmas associadas às aulas aplicadas, visto que consideramos seus conhecimentos prévios como sendo aqueles catalogados na literatura. Em outras palavras, ocorreu sim, uma busca do aspecto conceitual depreendido sobre ondas a partir da aplicação da Sequência Didática e verificamos como ela, ou sua possível adaptação, possa ter contribuído na métrica da aprendizagem da Física Ondulatória. Por essa razão nos obrigamos, na análise, ao diálogo com nosso referencial teórico à medida que surgem padrões de respostas que distam, um tanto mais ou um tanto menos, daqueles conceitos reconhecidos como representações mentais e, uma vez que se afastem destas concepções, estaria caminhando linearmente na direção do raciocínio nos moldes científicos.

No entanto, reavaliando as particularidades das turmas do diurno e do noturno consideramos razoável afirmar que a Sequência Didática alcançou parcialmente suas finalidades de transpor a barreira conceitual do senso comum no estudo de ondulatória. Parece-nos que a linguagem ofertada para o turno noturno, justamente onde fica evidente maiores fragilidades conceituais, não foi adequada, portanto, o ideal seria que se lhes dessem, aos alunos do noturno, um organizador prévio mais forte, condizente com a estrutura cognitiva do aluno.

Como recurso didático, acreditamos que a Sequência foi muito funcional. À medida em que os alunos participaram, houve interesse demonstrado por meio de perguntas com graus diferentes de curiosidade, bem como o momento em que se introduz um instrumento musical na aula, desde que seja de forma planejada e que ele seja portátil. Nesse contexto a expectativa é de que seja possível explorar uma ampla gama de possibilidades que trabalhe a motivação. Além de que o elemento música, extraída dos sons, é universal e ultrapassa as fronteiras da sala de aula.

\section{Referências bibliográficas}

AUSUBEL, David Paul; NOVAK, Joseph Donald; HANESIAN, Helen (1978). Psicologia educacional. Rio de Janeiro: Interamericana.

AUSUBEL, David Paul; NOVAK, Joseph Donald; HANESIAN, Helen (1980). Psicologia educacional. 2 ed. Rio de janeiro: Interamericana, $141 \mathrm{p}$.

AUSUBEL, David Paul (2003). Aquisição e retenção de conhecimentos: Uma perspectiva cognitiva, Lisboa: Editora Plátano.

BARDIN, Laurence (1977). Análise de conteúdo. 19 ed. Lisboa, Portugal: Edições 70.

BRUM, Wanderlei Pivato; SCHUHMACHER, Elcio (2014). A investigação dos conhecimentos prévios sobre geometria euclidiana, esférica e hiperbólica por meio da utilização de questionário. ItinerariusReflectionis, 10(1).

GOBARA, Shirley Takeco; VINHOLI JUNIOR, Airton José (2007). Modelos concretos e mapeamento conceitual: avaliando a compreensão de estudantes sobre célula. In: Encontro Nacional de Pesquisa em Educação em Ciências, 6, 2007, Florianópolis. Atas. Belo Horizonte: ABRAPEC.

KIEFER, Neci lolanda Schwanz; PILATTI, Luiz Alberto (2014). Roteiro para a elaboração de uma aula significativa. Revista Brasileira de Ensino ciência e Tecnologia, v. 7, n. 1.

Lemos, E. (2011). (Re)situando a teoria de aprendizagem significativa na prática docente, na formação de professores e nas investigações educativas em ciências. Revista Brasileira De Pesquisa Em Educação Em Ciências, 5(3), 2011. Acesso em fevereiro 28, 2021, de https://periodicos.ufmg.br/index.php/rbpec/article/view/4056 
MOREIRA, M. A (2012). O que é afinal aprendizagem significativa? Aula Inaugural do Programa de PósGraduação em Ensino de Ciências Naturais, Instituto de Física, Universidade Federal do Mato Grosso, Cuiabá, MT, 23 de abril de 2010. Qurriculum, Espanha.

MOREIRA, M. A (1985). Ensino e aprendizagem: enfoques teóricos. São Paulo, Editora Moraes, p. 61-73.

SAMPIERI, Hernandez Roberto; COLLADO, Carlos Fernádez; LUCIO, María del Pilar Baptista (2006). Metodologia de Pesquisa (4aed.) México: McGraw-Hill.

Esta obra está bajo una Licencia Creative Commons Attribución-NoCommercial 4.0 International

(cc) EY-NC 